\title{
Planning the walking and cycling network in Põlva, Estonia
}

\author{
M. Myllylä ${ }^{1} \&$ N. Karasmaa ${ }^{2}$ \\ ${ }^{1}$ Finnish Road Enterprise, Finland \\ ${ }^{2}$ Helsinki University of Technology, Transportation Engineering, Finland
}

\begin{abstract}
Promoting pedestrian and bicycle traffic in the Põlva region is an exemplary project in Estonia. The project is financed by the EU. A report of the initial stages of the project was completed at the end of 2005. The main planning target is a region-wide and multifunctional walking and cycling network. The project work was started in 2005. As the EU project in Põlva is intended to serve as a model for other towns and municipalities in Estonia, a manual titled "Planning pedestrian and bicycle traffic network in Municipalities" was issued, based on Finland's expertise and experience. No other similar manuals to our knowledge have been issued in Europe. The Põlva project is also a matching example of Finnish-Estonian cooperation.

Keywords: Finnish-Estonian cooperation, planning manual, sustainable traffic, walking and cycling network, pedestrian traffic.
\end{abstract}

\section{Background of the project}

In 2001, the Finnish Ministry of Transport and Communications launched a three-year project called Jaloin / by Foot for promoting pedestrian and bicycle traffic in Finland. The project was largely national; however it also included cooperation with various target groups as well as model action in municipalities. Among those a model action plan for sustainable traffic was applied in three municipalities and an urban district. The purpose of model action was to test environmentally sustainable and people friendly traffic solutions and to apply the principles of such model action in other locations.

The technical services board of Põlva town observed such model action in municipalities on their visit in Finland in autumn 2002. As a result of their visit, Põlva town and municipality launched a walking and cycling project financed by 
the EU in the Põlva region. The project served as a model for planning pedestrian and bicycle network by the needs of different traffic modes and groups as well as for categorising the network by the priority of its parts. The project benefited from Finnish expertise and experience in organising pedestrian and bicycle traffic. A group of three Finnish experts from Helsinki University of Technology and Finnish Road Enterprise assisted Estonian specialists by offering Finnish expertise, evaluating the project, and making it possible for Estonians to observe traffic networks in Finland.

\section{Project progress}

The project involved seminars, group work, and bicycle tours in the target area. The opening seminar was held in Põlva on 26 April 2004. Another meeting in Kerava, Finland took place on 25-26 August 2005. The meeting was organised by Kerava City Technology in cooperation with the assisting project experts from Helsinki University of Technology and Finnish Road Enterprise. The program included presenting cycling and walking networks in the towns of Kerava and Helsinki as well as model action organised by the Finnish Ministry of Transport and Communications in various municipalities.

During the bicycle trip in Kerava, press representatives were invited to observe the project and interview the participants. Estonians were mainly interested in the issues of separating pedestrian and bicycle roads, reducing motor traffic, bicycle parking and pavement materials. Other important issues in Estonia are the new traffic modes such as roller-skating. It was pointed out in Kerava that the maintenance of a pedestrian and bicycle traffic network after its construction is a challenging task.

As the EU project in Põlva is intended to serve as a model for other towns and municipalities in Estonia, a manual titled Planning bicycle and pedestrian traffic in Municipalities was published, based on Finland's expertise and experience [1]. No other similar manuals to our knowledge have been issued in Europe.

The Finnish-Estonian cooperation was successful and highly beneficial. An important factor was the readiness of Põlva town and municipality officials to promote pedestrian and bicycle traffic as valuable traffic modes, and the commitment of the municipality administrations to enhance those traffic modes by creating a region-wide network. Steps have already been taken to implement the plan. In many countries, the focus is still on motor traffic systems, while pedestrian and bicycle traffic is in danger of being neglected or isolated from other traffic planning or suffering from the lack of finances and decision-making as major motor transport projects are prioritised. Finland has a long tradition of pedestrian and bicycle traffic planning, however only a few region-wide pedestrian and bicycle traffic plans have been made. In Estonia the work has started from scratch. 


\section{The project as a part of regional development}

Regional planning in Põlva puts a high value on the physical well-being of its inhabitants. Town residents are encouraged to exercise all year round. The skiers from the region won three gold medals in the Winter Olympics 2006 in Turin. Two significant landscape entities in the region have been protected for purposes of tourism and recreation. The natural environment adds attraction to the pedestrian and bicycle network. Põlva town serves as a cultural and educational centre of the region. Organising traffic systems is closely related to the safety of school children and students (Figure 1).

Creating a pedestrian and bicycle network in Põlva municipality mostly serves tourism and recreation. The developmental strategy plan of the municipality highlights the need for road lighting and a pleasant environment. A selection of road materials also depends on the natural environment in the region as well as on the suitability of the materials and their maintenance.

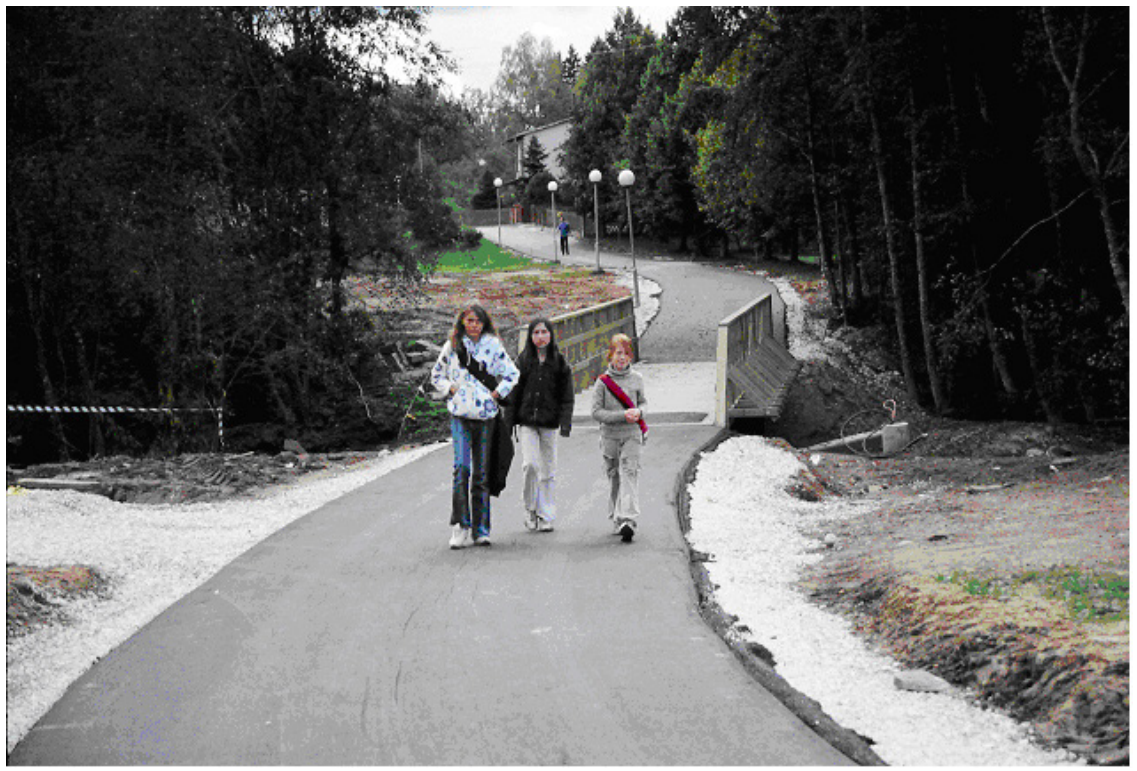

Figure 1: Young road users on a new school road in Põlva on the Europewide car-free day in 2005.

The central goals of developing the regional traffic system are:

- guaranteeing the safety and functionality of the traffic system;

- $\quad$ separating pedestrian and bicycle traffic from motor traffic; 
- $\quad$ reducing the number of main road and pedestrian/bicycle traffic intersections and increasing their safety.

No major roads are planned to be built in the Põlva municipality, so the pedestrian and bicycle traffic system is developed within the existing road and street network. The pedestrian and bicycle traffic system will change the overall impression and environment of the town centre and increase its viability.

\section{Factors influencing pedestrian and bicycle traffic}

The population of the target area is some 10000 inhabitants [2, 3]. The percentage of young people is above the average. Municipality roads are actively used by school children and free-time activists. A viable pedestrian and bicycle traffic system is believed to promote tourism and economy in the region.

The undulating landscape of the region is a challenge when planning the network, at the same time as it allows change to its users. The target area is relatively small. Daily trips do not exceed 2-5 kilometres and are made by walking or cycling. Schools and offices are concentrated to a small area. As everywhere else, the way people move depends on economical and convenience factors. The traffic system also affects the choice of traffic modes. The relatively high price of bicycles and the lack of bicycle paths have limited cycling and investments made into it.

Only little statistical data is available of pedestrian and bicycle traffic in Põlva. At the early stages of the project, school children were interviewed about their traffic habits. The small size of the project area and its population has made pre-project planning and decision-making easier.

\section{Goals of pedestrian and bicycle network and principles of planning}

Walking and cycling is often a workable alternative to motor traffic. Walking, cycling and roller-skating are a central part of modern active life. Promoting pedestrian and bicycle traffic is regarded as a global trend in sustainable development. By increasing pedestrian and bicycle traffic, a contribution is made to safer travelling. The responsibility for guaranteeing traffic safety lies on public authorities when planning their action. The experience gained in Põlva and elsewhere shows that roads with reduced traffic are safer for both pedestrians and cyclists, although they are not always the straightest route to the destination (Figure 2).

The project served as a model for planning pedestrian and bicycle network by the needs of different traffic modes and groups as well as for categorising the network by the priority of its parts. The main goal was establishing a userfriendly pedestrian and bicycling network.

Parts of the network serve the needs of pedestrians, cyclists and roller-skaters as well as bicycle parking. The network is connected to the motor traffic and 
public transportation system. The main principles of planning the pedestrian and bicycle traffic system in Põlva region are the following:

- $\quad$ forming a region-wide and continuous pedestrian and bicycle traffic system;

- $\quad$ providing connection to homes, schools, offices and recreational services;

- $\quad$ separation of the network from motor traffic;

- $\quad$ safety of intersections with motor traffic;

- $\quad$ utilizing streets with reduced traffic as parts of the pedestrian and bicycle traffic system;

- $\quad$ adding attraction by benefiting from the landscape;

- $\quad$ involving different user groups.

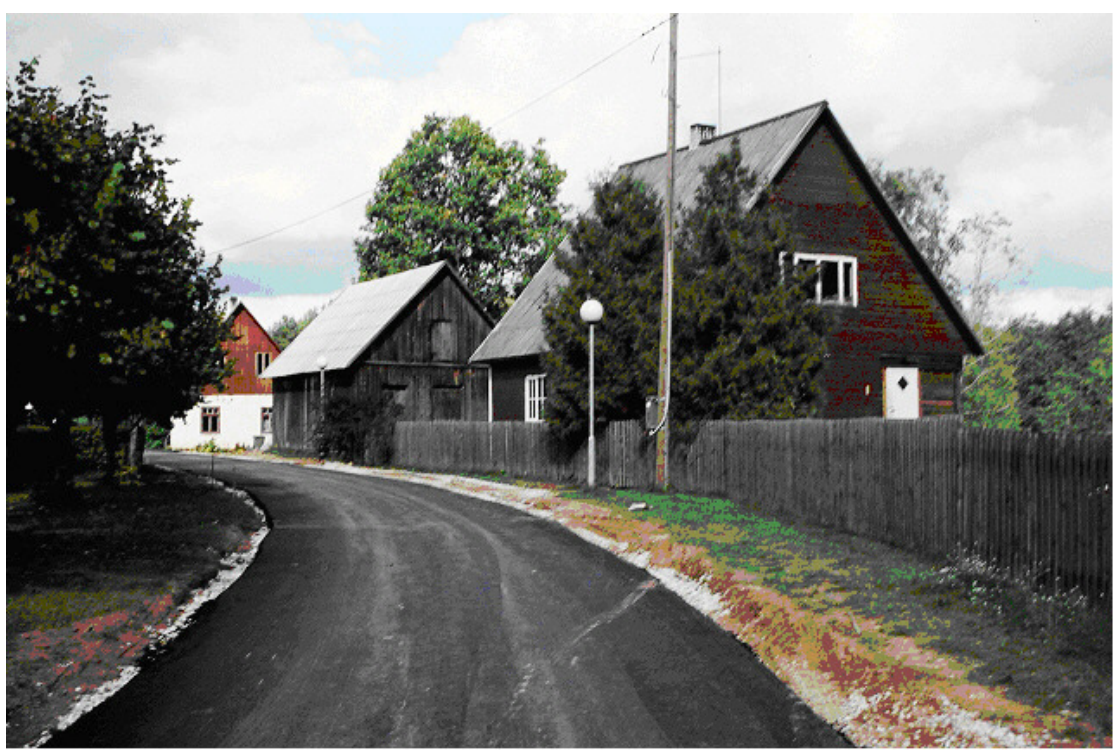

Figure 2: The use of roads with reduced traffic as walking and cycling roads may be increasing in modern communities. Põlva in 2005.

\section{Categorising pedestrian and bicycling network based on road use}

The network was divided into the following categories based on the road use:

- $\quad$ school roads,

- recreational roads,

- roller-skating roads,

- daily travelling roads. 
Standards for safety, maintenance, cross section, surface, environment and services depend on the road use. Different roads may serve a variety of functions. More advanced systems and specially designed roads enable to take into account the particular needs of user groups.

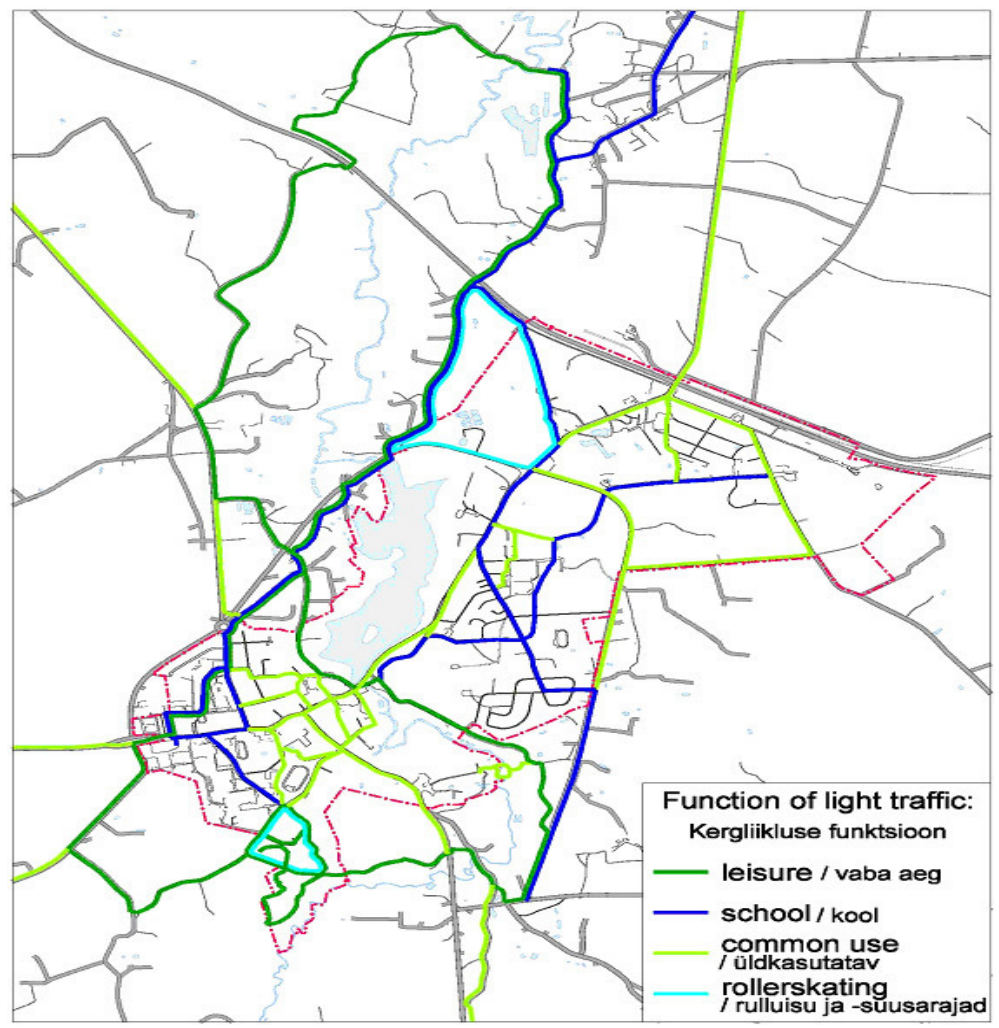

Figure 3: The pedestrian and bicycling network plan in the Põlva region, network categorised by user groups.

\section{Categorising pedestrian and bicycling network based on priority}

Depending on its use, importance and user rate, the network could be divided into 2-3 categories of priority, similar to the ones applied in motor traffic networks. The Põlva region was divided into main walking and cycling roads and secondary roads. The main roads were the multifunctional ones. Such categories help regulate the financing and timing of the network. The total length of the target network is 64 kilometres, with the main roads covering 16 kilometres. 


\section{Categorising pedestrian and bicycling network based on separation principle}

From a technical point of view, the network can be divided into categories based on the connection of the pedestrian and bicycle traffic and motor traffic roads. The following separation models were applied in Põlva:

1. separate pedestrian and bicycle roads, 14 per cent;

2. bicycle roads on sidewalk separated from the main road by a separation lane, 70 per cent;

3. bicycle roads on sidewalk separated from the main road by a kerb or railing;

4. separation marked on the ground, 2 per cent;

5. roads of reduced traffic as pedestrian and bicycle traffic roads, 10 per cent.

Simultaneous planning of land use and traffic systems is a relatively new tradition in Põlva, which explains the problem with land reservation for pedestrian and bicycle traffic in many places. As the planning of land use will progress, creating a separate network will be easier. Within some of the most urgent projects, the quality of traffic environment has suffered from pedestrian and bicycle traffic connections being placed too close to the main road, or from allowing poor visibility.

\section{Incorporating other elements of walking and cycling network}

In planning the pedestrian and bicycle network in Põlva, the number of pedestrian/bicycle traffic and motor traffic intersections was minimised, so as to increase the number of interchanges and traffic lights. Altogether eight intersections required more careful planning. Also, in eight locations a need for bicycle parking was observed.

\section{Project financing}

The pedestrian and bicycle network plan in Põlva region is implemented in stages. The project is financed from a variety of sources. The main financial supporters are Põlva town and municipality. In places where the sidewalk and bicycle road are a part of the main road, funding is provided by the state. In various road projects, walking and cycling network is observed as part of a larger framework of intersections and connections with the main road. Such traffic arrangements can be incorporated in larger road projects and financed by the project. A pedestrian and bicycling network plan is a useful tool for monitoring such particular traffic arrangements. 
A pedestrian and bicycle traffic system is a part of the technical development of the municipality in the target area and should be financed and implemented by the municipality. The technical support and structures are regularly renewed in municipalities. Such changes are especially relevant in present-day Estonia. At the same time such changes enable to develop and renew pedestrian and bicycle traffic systems in cooperation with the street owner and the owner of the pipes and cables under the street. For occasional pedestrian and bicycle traffic projects such as bridges and distant connections, special financial means should be provided from the municipality budget. Such projects should also be part of the overall action plan and economical strategy of the state and municipality, so that pedestrians' and bicyclers' needs can be considered. However a special pedestrian and bicycle traffic plan is needed at any rate.

Pedestrian and bicycling network projects are entitled to European Union's funding. A model target in such projects could be preserving and developing village life by enhancing the state of the pedestrian and bicycle traffic system. Funding can also be received for developing natural or physical environment or promoting tourism and economy in the region. In such projects, the pedestrian and bicycle traffic system is often included in the overall developmental strategy. Various pedestrian and bicycle traffic systems are a part of major infrastructural projects financed by the EU.

\section{References}

[1] Theme Plan of Pedestrian and Bicycle Traffic in Polva Town and Surroundings. Polva City Government and Polva Municipality Government. Polva 2005.

[2] Põlvamaa County plan (Põlva maakonna planeering)

[3] Environmental conditions directing the human settlement and land use in Põlva County. Põlva 2003. (Põlva maakonna Asustust ja maakasutust suunavad keskkonnatingimused. Põlva 2003) 